Biomacromolecules. 2016 October 10; 17(10): 3205-3212. doi:10.1021/acs.biomac.6b00900.

\title{
Mapping Optimal Charge Density and Length of ROMP-based PTDMs for siRNA Internalization
}

\author{
Leah M. Caffrey ${ }^{\dagger, \#}$, Brittany M. deRonde ${ }^{\dagger, \#}$, Lisa M. Minter ${ }^{\S, \ddagger}$, and Gregory N. Tew ${ }^{\dagger, \S, \ddagger}$ \\ tDepartment of Polymer Science and Engineering, University of Massachusetts Amherst, \\ Amherst, MA 01003 \\ §Department of Veterinary and Animal Sciences, University of Massachusetts Amherst, Amherst, \\ MA 01003 \\ ¥Molecular and Cellular Biology Program, University of Massachusetts Amherst, Amherst, MA \\ 01003
}

\begin{abstract}
A fundamental understanding of how polymer structure impacts internalization and delivery abilities of biologically relevant cargoes, particularly siRNA, is of critical importance to the successful design of improved delivery reagents. Herein we report the use of ring-opening metathesis polymerization (ROMP) methods to synthesize two series of guanidinium-rich protein transduction domain mimics (PTDMs): one based on an imide scaffold that contains one guanidinium moiety per repeat unit and another based on a diester scaffold that contains two guanidinium moieties per repeat unit. By varying both the degree of polymerization and, in effect, the relative number of cationic charges in each PTDM, the performances of the two ROMP backbones for siRNA internalization were evaluated and compared. Internalization of fluorescently labeled siRNA into Jurkat $\mathrm{T}$ cells demonstrated that FITC-siRNA internalization had a charge content dependence, with PTDMs containing approximately 40 to 60 cationic charges facilitating the most internalization. Despite this charge content dependence, the imide scaffold yielded much lower viabilities in Jurkat T cells than the corresponding diester PTDMs with similar numbers of cationic charges, suggesting that the diester scaffold is preferred for siRNA internalization and delivery applications. These developments not only improve our understanding of the structural factors necessary for optimal siRNA internalization, but will also guide the future development of optimized PTDMs for siRNA internalization and delivery.
\end{abstract}

\section{Graphical Abstract}

\footnotetext{
\#Denotes equal contribution
} 

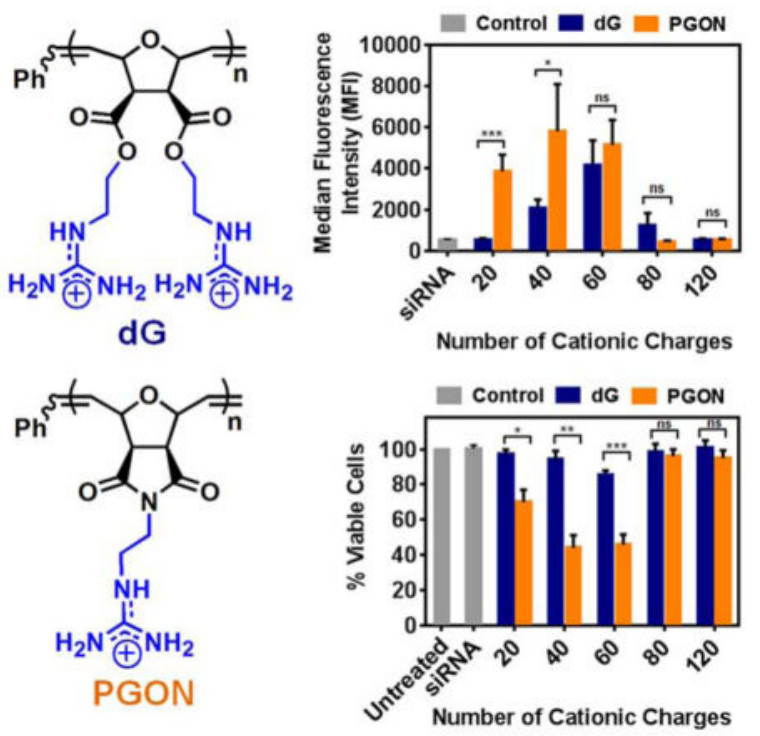

\section{Introduction}

Designing robust and reliable therapeutic delivery agents is an on-going challenge in the biochemical and biomedical fields. Although cell membranes serve as protective barriers for cells, the ability to transverse them and deliver biologically important molecules, such siRNA, microRNA, pDNA, proteins, antibodies, or small polar molecules, would enable the development of more sophisticated therapeutic treatment options. ${ }^{1,2}$ In efforts to develop improved materials to facilitate cellular internalization, many researchers have turned to nature for inspiration by studying proteins with translocation abilities along with their shorter peptide counterparts: protein transduction domains and cell-penetrating peptides. ${ }^{1,2}$

A protein transduction domain (PTD), a type of cell-penetrating peptide (CPP), is a protein sequence containing cation-rich amino acid residues, such as arginine and lysine, that enables the protein to cross cell membranes. ${ }^{3-5}$ Two examples of proteins containing PTDs that have been extensively studied are HIV-1 TAT (transactivator of transcription) ${ }^{6-7}$ and the Antennapedia Homeodomain. ${ }^{8}$ Through many thoughtfully-designed structure activity relationship studies, the cationic segments have been shown to be the essential aspect that enables it to translocate into cells and deliver biologically relevant cargo. ${ }^{3-5}$ The aforementioned internalization and delivery capabilities were retained, and in some cases even improved, through the use of truncated sequences, ${ }^{9}$ materials lacking secondary structure, ${ }^{4,5}$ and materials that have non-peptidic backbones. ${ }^{10}$

These studies ultimately led to the exploration of fully synthetic systems, which aim to capture only the key features of PTDs necessary for sufficient internalization and delivery capabilities, ${ }^{3-5,9,11}$ these include number of cationic charges, often implemented through the incorporation of guanidinium groups and sometimes a segregated, hydrophobic segment. ${ }^{1,12}$ To this end, researchers have recently explored the use of polymeric scaffolds, leading to the development of synthetic mimics referred to as protein transduction domain mimics (PTDMs) or cell-penetrating peptide mimics (CPPMs). ${ }^{3,13-17}$ Synthetic PTDMs offer many 
advantages over their peptide counterparts. Avoiding a peptide backbone eliminates issues of proteolysis as well as the need for solid-phase synthesis. It also opens up a wider range of structural possibilities and synthetic chemistries that can be used. ${ }^{12,13}$ To date, polycarbonate, ${ }^{10,18}$ polynorbornene/polyoxanorbornene, ${ }^{19-23}$ polymethacrylamide, ${ }^{24}$ polydisulfide, ${ }^{25-29}$ and oligophosphoester ${ }^{30}$ scaffolds have been successfully used. ${ }^{10,18-30}$

Contributing to the improvement and understanding of PTDMs, our research group has studied the polyoxanorbornene scaffold for its internalization and delivery capabilities. Our group has designed PTDMs using ring-opening metathesis polymerization (ROMP) due to its fast and efficient nature resulting in narrow dispersities and good control over molecular weight distributions. ${ }^{12,31-32}$ Extensive work has been devoted to understanding how factors such as number of cationic charges ${ }^{33,34}$, polymer chain length ${ }^{33-36}$, hydrophobicity ${ }^{35,36}$, aromaticity ${ }^{37}$, pi-electronics ${ }^{38}$, and sequence specificity of cationic and hydrophobic moieties ${ }^{39}$ impact membrane interactions, PTDM internalization, and the delivery of bioactive cargoes. One area of focus has been the internalization and delivery of small interfering ribonucleic acid (siRNA). ${ }^{34,40}$

siRNA, or small-interfering RNA, is a double-stranded RNA molecule that is most notable for its role in RNA interference (RNAi), which uses siRNA to interfere and silence the expression of certain genes in cells through the transient inhibition of protein production. ${ }^{41}$ Silencing specific genes though RNAi is particularly useful in exploring molecular pathways in $\mathrm{T}$ cells, a cell type that holds essential functions in the immune system, since protein levels can be temporarily reduced and the effect on downstream products can be studied. ${ }^{42}$ It may also be advantageous for use in therapeutic applications. ${ }^{43}$

We previously reported that our synthetic structures, rich in cationic charge vital for effective delivery and membrane translocation, $1,5-7,9,44$ are able to promote fluorescein isothiocyanate (FITC) labeled siRNA internalization into greater than $90 \%$ of the cell populations tested, demonstrating the robust nature of this polymer system while maintaining high cell viability. ${ }^{12,34,40}$ In addition, we have been able to achieve greater than $50 \%$ reduction of NOTCH1 protein expression in human primary $\mathrm{T}$ cells through the successful delivery of NOTCH1-specific siRNA. ${ }^{12,34,40}$ To date, all reported delivery data from our group utilized a diester, oxanorbornene-based scaffold. Recently, we demonstrated the correlation between FITC-siRNA internalization and siRNA-enabled knock-down of NOTCH1, documenting FITC-siRNA internalization as a reasonably predictive screening tool for this class of PTDM internalization in T cells. ${ }^{34}$

In order to better understand how polymer backbone architecture impacts siRNA internalization, the diester scaffold (dG) was compared to the initial imide-based scaffold, polyguanidinium oxanorbornene (PGON). ${ }^{22,23}$ In 2008, the Tew group and collaborators reported the synthesis of PGON, which exhibited potent antimicrobial activity against both Gram-positive and Gram-negative bacteria. ${ }^{22}$ Until now, this scaffold had not been explored for bioactive cargo delivery. By comparing the two scaffolds, it was possible to explore how the backbone, which determines guanidine density, affects the PTDMs' ability to promote siRNA internalization (Figure 1). FITC-siRNA was used for these experiments as a control to monitor siRNA internalization in Jurkat $\mathrm{T}$ cells. This method is useful for exploring 
therapeutic potential as well as toxicity of compounds while allowing the siRNA to be tracked from the fluorescent tags it contains. Through systematic structural tuning, these two sets of PTDMs were used to explore the role of guanidinium density and the degree of polymerization (DP), or chain length, on siRNA complexation and internalization ability.

\section{Experimental}

\section{Monomer Synthesis and Characterization}

The $\mathbf{d G}$ monomer was synthesized using a two-step process previously reported by our group. ${ }^{34}$ In brief, oxanorbornene anhydride was ring-opened using 1,3-di-boc-2-(2hydroxyethyl)guanidine alcohol and 4-dimethylaminopyridine (DMAP) as a catalyst. The 1,3-di-boc-2-(2-hydroxyethyl)guanidine was added to the monomer using 1-ethyl-3-(3dimethylaminopropyl)carbodiimide (EDC) coupling. The resulting monomer was purified using a CombiFlash system with ethyl acetate/dichloromethane $\left(\mathrm{CH}_{2} \mathrm{Cl}_{2}\right)(1 / 9$, v/v) as the eluent and subsequently analyzed by ${ }^{1} \mathrm{H}$ NMR spectroscopy, ${ }^{13} \mathrm{C}$ NMR spectroscopy, and mass spectrometry (MS) to assess the chemical composition and purity. Detailed synthetic procedures and all characterization data are provided in the supporting information (section II, Figure S1).

The PGON monomer was synthesized using a process previously reported by our group. ${ }^{35,37}$ In brief, 1,3-di-boc-2-(2-hydroxyethyl)guanidine alcohol was added to oxanorbornene imide using triphenylphosphine $\left(\mathrm{Ph}_{3} \mathrm{P}\right)$ and diisopropyl azodicarboxylate (DIAD). The resulting product was then recrystallized in hot methanol and then further purified using a CombiFlash purification system with ethyl acetate/hexanes $(6 / 4, \mathrm{v} / \mathrm{v})$ as the eluent and subsequently analyzed by ${ }^{1} \mathrm{H}$ NMR spectroscopy, ${ }^{13} \mathrm{C}$ NMR spectroscopy, and mass spectrometry (MS) to assess the chemical composition and purity. Detailed synthetic procedures and all characterization data are provided in the supporting information (section II, Figure S2).

\section{PTDM Synthesis and Characterization}

All homopolymer PTDMs were synthesized by ROMP using Grubbs' third generation catalyst following previously described methods. ${ }^{34-37}$ In brief, the monomers and catalyst were dissolved separately in $\mathrm{CH}_{2} \mathrm{Cl}_{2}$ and degassed using freeze-pump-thaw methods. To initiate the polymerization, the cationic monomer was cannulated into the catalyst solution in Boc-protected form in order to prevent premature termination of polymerizations due to catalyst coordination and to allow for sufficient solubility in organic solvents. Polymers were quenched with ethyl vinyl ether, precipitated, and subsequently deprotected using a 1:1 ratio of $\mathrm{CH}_{2} \mathrm{Cl}_{2}$ :trifluoroacetic acid (TFA). Excess TFA was removed by azeotropic distillation with methanol. All $\mathbf{d G}_{\mathbf{n}}$ polymers were dialyzed against reverse osmosis (RO) water using dialysis membranes with a molecular weight cutoff (MWCO) of 100-500 g/mol until the water conductivity was $<0.2 \mu \mathrm{S}$. Finally, all polymers were dissolved in water and subsequently aqueous filtered and lyophilized. All PTDMs were characterized by ${ }^{1} \mathrm{H}$ NMR and gel permeation chromatography (GPC) to assess chemical compositions and molecular weight distributions, respectively. Detailed synthetic procedures and all characterization data are provided in the supporting information (section II, Figures S3-S6). 


\section{Jurkat T Cell Culture and FITC-siRNA Internalization}

Jurkat T cells were cultured in RPMI 1640 supplemented with 10\% (v/v) fetal bovine serum (FBS), $100 \mathrm{U} / \mathrm{mL}$ non-essential amino acids, $100 \mathrm{U} / \mathrm{mL}$ sodium pyruvate, $100 \mathrm{U} / \mathrm{mL}$ penicillin, and $100 \mathrm{U} / \mathrm{mL}$ streptomycin. These cells were incubated at $37^{\circ} \mathrm{C}$ with $5 \% \mathrm{CO}_{2}$ and passaged 24 hours prior to experimentation. On the day of the experiment, PTDMs and FITC-siRNA were mixed at an N:P ratio of 8:1 (50 nM siRNA/well) and incubated for 30 minutes at room temperature prior to adding them drop-wise to the cells $\left(4 \times 10^{5}\right.$ cells/well; 1 $\mathrm{mL}$ total volume) in a 12 well plate. Cells were incubated at $37^{\circ} \mathrm{C}$ with $5 \% \mathrm{CO}_{2}$ in serumcontaining media for four hours prior to analysis by flow cytometry. Cell viability was assessed using 7-AAD staining.

\section{Results and Discussion}

\section{Molecular Design and Characterization}

In this study, ring-opening metathesis polymerization (ROMP) was used to synthesize PTDMs based on a diester (dG) or an imide (PGON) scaffold in order to study the role polymer backbone plays in siRNA internalization. The structures of the resulting polymeric PTDMs are documented in Figure 1. The dG PTDMs contain two guanidinium groups per repeat unit whereas the PGON PTDMs contain one guanidinium group per repeat unit. As a result, the DPs were selected to control for overall PTDM chain length as well as the relative number of guanidinium moieties (Figure 1c). All PTDMs were characterized by ${ }^{1} \mathrm{H}$ NMR and GPC as documented in the supporting information (Figures S7-S10). A molecular weight summary of the Boc-protected polymers is outlined in Table 1. Plots of number average molecular weight as a function of monomer/initiator ratio for both the $\mathbf{d G}$ and PGON PTDM series gave linear trend lines with $\mathrm{R}^{2}$ close to one (Figures $\mathrm{S} 11$ and S12). In addition, dispersities of these materials remained below 1.2 for all samples. Taken together, this data verifies the good polymerization control often exhibited by ROMP. Previous work in this area documented the effect that dG PTDM length had on siRNA internalization and suggested that there was an optimal relative charge content for maximum internalization and delivery. ${ }^{34}$ The current work expands these studies to explore the impact polymer backbone has on siRNA internalization at DPs up to 60 units for the dG series and 120 units for the PGON series as well as comparing the two backbones in side-by-side assays.

\section{Biophysical Characterization of Polymers}

Prior to performing FITC-siRNA internalization studies, the PTDMs were initially studied using model vesicle systems to assess polymer-membrane interactions as they relate to transduction. Model membrane systems are useful because they represent simpler systems than cells and remove complexities of active transport, such as endocytosis, and receptormediated uptake; they focus primarily on mimicking direct translocation and membrane interactions. Through this biophysical screening process, PTDMs with poor membrane interaction can be removed from the testing pool. Similar studies have been used in the past by Tew and coworkers, ${ }^{23,35,37,38}$ Matile and coworkers, ${ }^{23,28,44-48}$ and Almeida and coworkers ${ }^{49,50}$ to study the way molecules interact with model membranes. For these studies, egg yolk phosphatidylcholine (EYPC) lipids were swelled in the presence of carboxyfluorescein, to form dye-filled vesicles. ${ }^{22,23,35,37,45-50}$ Carboxyfluorescein is self- 
quenched at high concentrations and its release from model membranes can be monitored using either a fluorimeter, or in the case of a more high-throughput screening method, a fluorescence plate reader. ${ }^{38}$ Dye leakage was monitored as a function of PTDM concentration and data points were fitted using the Hill Equation to determine $\mathrm{EC}_{50}$ values, which are the effective concentration at which $50 \%$ of the dye is released. ${ }^{23,35,37,38,45,46-52}$ Detailed information in regards to plots and $\mathrm{EC}_{50}$ calculations can be found in the supporting information (section IV, Figures S15-28). All $\mathrm{EC}_{50}$ values were between 0.76 and $22 \mathrm{nM}$. In comparison, previous studies performed by our group demonstrated that poorperforming PTDMs have $\mathrm{EC}_{50}$ values greater than or equal to $200 \mu \mathrm{M} .{ }^{35}$ This demonstrates that all PTDMs used in this study interact strongly with these model membranes and were therefore studied further.

To assess aggregation properties of the PTDMs in solution, size and zeta potential measurements were taken in aqueous solution using a zetasizer. In terms of size, the hydrodynamic diameter of the polymers in solution were less than $\mathrm{D}_{\mathrm{H}}=400 \mathrm{~nm}$, with longer PTDMs having larger sizes in solution than shorter PTDMs. PTDMs of similar charge contents were found to be non-statistically different in size. With respect to zeta potential, all PTDMs exhibited similar zeta potentials (50-75 mV), with no PTDM length or charge content dependence. Experimental details can be found in the supporting information (section V, Figures S29-S30). Preliminary size and zeta potential measurements were also taken of select PTDM/siRNA complexes using PTDMs representing extremes and midpoints in DP ( $\mathbf{d G}_{\mathbf{1 0}}, \mathbf{d G}_{\mathbf{2 0}}, \mathbf{d G}_{\mathbf{6 0}}$ and $\mathbf{P G O N} \mathbf{2 0}_{\mathbf{2 0}}, \mathbf{P G O N} \mathbf{4 0}_{\mathbf{4 0}}$, and $\left.\mathbf{P G O N} \mathbf{1 2 0}_{\mathbf{1 2 0}}\right)$. All measured complexes exhibited similar size distributions $\left(\mathrm{D}_{\mathrm{H}}=160-300 \mathrm{~nm}\right)$ and zeta potentials $(35-38 \mathrm{mV})$. Experimental details can be found in the supporting information (section V, Figure S31).

\section{FITC-siRNA Internalization in Jurkat T Cells}

In order to explore the role of polymer backbone architecture, five dG PTDMs ( $\mathrm{n}=10,20$, 30, 40, and 60) and seven PGON PTDMs ( $\mathrm{n}=10,20,30,40,60,80$, and 120) were selected for study to control for both DP and number of cationic charges. Jurkat $\mathrm{T}$ cells were selected as the model system given the challenges associated with delivery to T cells. ${ }^{33-40,53-59}$ FITC-siRNA was used to establish trends in siRNA internalization for both series in Jurkat $T$ cells. The N:P ratio for these experiments, which is the ratio of the number of positively charged guanidinium groups in the PTDMs to the number of negatively charged phosphate atoms in the FITC-siRNA, was set at 8:1, a ratio that was previously optimized by our group. ${ }^{40}$ The same N:P ratio was used for the PGON series as well to establish the same parameters for comparison. The selection of this N:P ratio was further supported from the results of gel retardation assays, which demonstrated that all PTDMs, with the exception of $\mathbf{d G}_{\mathbf{6 0}}$ and $\mathbf{P G O N}_{\mathbf{1 2 0}}$, fully bound siRNA at N:P ratios of 4:1 or greater (section III, Figures S13-S14).

A summary of FITC-siRNA internalization for the $\mathbf{d G}$ and PGON PTDM series is shown in Figure 2, where Figures 2a and 2c represent the data when compared based on PTDM chain length and Figures $2 b$ and $2 d$ represent the data when compared based on relative theoretical average number of cationic guanidinium groups. For both representations, data was compared based on the percentage of the cell population receiving FITC-siRNA (Figures 2a 
and $2 \mathrm{~b}$ ) and the median fluorescence intensity, or MFI (Figures $2 \mathrm{c}$ and 2d), which reflected the relative amount of siRNA internalized.

Examining first the $\mathbf{d G}$ polymer series, it was evident that $\mathbf{d G}_{\mathbf{2 0}}$ and $\mathbf{d G}_{\mathbf{3 0}}$ delivered FITCsiRNA to the largest percentage of the cell population, approximately $60-85 \%$, and had the largest MFIs (2100 and 4200, respectively). At larger DPs ( $\mathbf{d G}_{\mathbf{4 0}}$ and $\left.\mathbf{d G}_{\mathbf{6 0}}\right)$, FITC-siRNA internalization decreased dramatically, indicating that there was an optimal relative charge content or polymer chain length required for maximum siRNA internalization with this PTDM. Similarly within the PGON series, FITC-siRNA internalization increased significantly as both the chain length and number of cationic residues increased from 10 to 20 repeat units. As the chain length and cationic charge content increased further, PGON polymers with repeat units of 30, 40 and 60 still performed well, allowing internalization of FITC-siRNA into greater than $60 \%$ of the cells. In addition, these polymer/FITC-siRNA complexes, especially with $\mathbf{P G O N}$ 40 and PGON $\mathbf{6 0}$, produce some of the highest MFIs observed in these experiments, 5800 and 5100, respectively. Then, as the PGON chain length increased to 80 and 120 repeat units, both the percentage of FITC-siRNA positive cells and MFI decreased dramatically, with the percentage of cells receiving siRNA decreasing to less than $30 \%$ and the MFIs decreasing to 400 for $\mathbf{P G O N}_{\mathbf{8 0}}$ and 600 for PGON $_{120}$.

When the dG and PGON series were compared based on PTDM chain length, it was found that the $\mathbf{d G}$ series saw a dramatic decrease in internalization, both in terms of percent positive cells and MFI, with PTDMs greater than 30 repeat units $\left(\mathbf{d G}_{\mathbf{4 0}}\right.$ and $\left.\mathbf{d G}_{\mathbf{6 0}}\right)$ whereas this decrease did not occur for PGON until PTDMs had greater than 60 repeat units PGON $_{\mathbf{8 0}}$ and PGON $\left._{\mathbf{1 2 0}}\right)$. Given this broader window of high performing PGON-based PTDMs, this data illustrates that more PGON PTDMs are able to effectively facilitate FITCsiRNA internalization than the PTDMs of the dG series. However, when the two series are evaluated based on the relative number of cationic charges, it is evident that both series share the same relative charge content dependence on FITC-siRNA internalization when the PTDMs contain greater than 20 guanidinium moieties. It should be noted, though, that the longer $\mathbf{P G O N}_{\mathbf{2 0}}$ PTDM significantly outperforms its $\mathbf{d G}_{\mathbf{1 0}}$ counterpart containing the same number of charges, indicating that the longer polymer is more effective with this charge content. At matching charge contents of 40 and larger, however, the dG and PGON polymers perform identically in terms of the percentages of cells receiving FITC-siRNA and resulting MFIs, with the exception of $\mathbf{P G O N} \mathbf{4 0}$ producing a higher MFI than $\mathbf{d G}_{\mathbf{2 0}}$. Both series show a turnover in efficiency when the PTDMs contain more than an average of 60 cationic charges, which suggests that an optimal charge content is required under these experimental conditions to maximize both the amount of FITC-siRNA that is able to enter cells as well as the percentage of the cell population receiving FITC-siRNA. Due to the similarity in performance between the two series based on matching charge content, the data also suggests that the PTDM backbone has less significance in determining siRNA internalization capability than the comparative number of cationic guanidinium-based charges. 


\section{Viability and Toxicity Studies}

Despite similarities in enabled FITC-siRNA internalization, stark differences were observed in the overall cytoxicities of the dG/FITC-siRNA and PGON/FITC-siRNA complexes, as displayed in Figure 3.

Observing the dG series first, it was evident that each of these polymers exhibits high cell viabilities, above $90 \%$, indicating that the dG/FITC-siRNA complexes were largely nontoxic; however, a much different trend was seen within the PGON series. As the DP for PGON was increased from 10 repeat units to 60 repeat units, the toxicity increased to yield only $50 \%$ viable cells for the $\mathbf{P G O N}_{60} /$ FITC-siRNA complex. While the viabilities observed between dG and PGON up to 30 repeat units are not significantly different, the strong downward trend in viability for PGON $_{40} /$ FITC-siRNA and PGON $_{60} /$ FITC-siRNA made them more lethal to the cells than $\mathbf{d G}_{\mathbf{4 0}} /$ FITC-siRNA and $\mathbf{d G}_{\mathbf{6 0}} /$ FITC-siRNA. In terms of cationic charge content, PGON/FITC-siRNA complexes were clearly more cytotoxic than dG complexes at 20, 40, and 60 charges. While PGON $_{40} /$ FITC-siRNA and PGON $_{60} /$ FITCsiRNA were shown to be the most toxic complexes to cells, the complexes containing two longer PTDMs ( PGON $_{\mathbf{8 0}} /$ FITC-siRNA and PGON $_{120} /$ FITC-siRNA complexes) exhibit high cell viabilities above 90\%, similar to what is observed in cells treated with $\mathbf{P G O N}_{\mathbf{1 0}}$ /FITCsiRNA. These polymers produce the same viabilities as their $\mathbf{d G}$ counterparts containing the same number of charges: $\mathbf{d G}_{\mathbf{6 0}}$ and $\mathbf{d G}_{\mathbf{8 0}}$. It should be noted that these four polymers were the least effective of the two series at delivering FITC-siRNA, producing very small MFIs in the tested populations.

In order to assess if the PGON-based PTDMs were responsible for the toxicity observed in Figure 3, viability screening was performed in the absence of FITC-siRNA. For these experiments, the PTDM concentration tested was consistent with the concentration used in the internalization experiments (Figure 2). The results of these experiments are shown in Figure 4. As observed, cells treated with only $\mathbf{d G}$ polymers maintained viabilities even higher than when complexed with FITC-siRNA, close to $100 \%$ viable cells; this confirms that the $\mathbf{d G}$ polymers themselves have no cytotoxic effects in the given experimental timeframe. Somewhat surprisingly, the same results were seen within the PGON series, which also exhibited viabilities around $100 \%$ in cells treated with the polymer only, indicating that these polymers alone are nontoxic.

Given the limited toxicity of the PTDMs themselves, it is likely that differences observed in cell viabilities resulting from treatment with the dG/FITC-siRNA complexes and the PGON/FITC-siRNA complexes are related to the ways in which the complexes interact with cells or to the quantity of siRNA that the PTDMs are able to help internalize since it is known that too much intracellular siRNA can be toxic. ${ }^{60-65}$ For example, when considering the data in Figures 2c-d and 3, the most toxic PGON samples $\left(\mathbf{P G O N}_{\mathbf{4 0}} /\right.$ FITC-siRNA and PGON $_{60}$ /FITC-siRNA) also facilitate the most siRNA internalization. In an effort to better understand whether the amount of siRNA internalized was related to the observed toxicity documented in Figure 3, two PTDMs, $\mathbf{d G}_{\mathbf{2 0}}$ and $\mathbf{P G O N} \mathbf{4 0}$ with the same total number of guanidines, were further explored for their siRNA internalization ability and cytotoxicity. These two PTDMs represent extremes in cell viability when complexed with siRNA and 
also allow comparison of DP (chain length) and number of cationic charges in PTDM activity. A new series of internalization studies were performed, using the same complex $\mathrm{N}: \mathrm{P}$ ratio of $8: 1$, with both increasing and decreasing concentrations of total PTDM/FITCsiRNA complex. These data were compared to those of the internalization studies detailed in Figure 2 , which were originally performed using $0.5 \mu \mathrm{M}$ total polymer concentration. The results of this new study are shown in Figure 5.

As expected, the $\mathbf{d G}_{\mathbf{2 0}} /$ FITC-siRNA complexes are never toxic within this tested

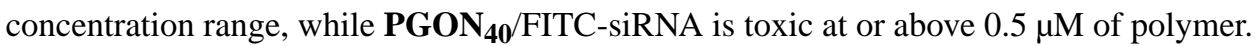
However, when the overall complex concentration was lowered to $0.35 \mu \mathrm{M}$, a noticeable increase in viability was observed for the $\mathbf{P G O N}_{\mathbf{4 0}} /$ FITC-siRNA complex. Initially, this would appear to correspond with the lesser amount of siRNA internalization that this particular concentration of complex promotes; however, the resulting MFIs associated with internalized siRNA at each of the concentrations tested are not consistent with this hypothesis. The total MFI for the PGON $\mathbf{4 0}_{\mathbf{4}}$ /FITC-siRNA complexes at $0.35,0.50,1.00$, and $1.50 \mu \mathrm{M}$ are statistically the same, despite the clear differences observed in viability at increasing concentrations. The MFIs produced from the $\mathbf{d G}_{\mathbf{2 0}} /$ FITC-siRNA complexes are also similar to the MFIs resulting from the $\mathbf{P G O N}_{40}$ /FITC-siRNA complexes at $0.50,1.00$, and $1.50 \mu \mathrm{M}$ polymer used, yet the observed cell viabilities are quite different. Taken as a whole, these data suggest excessive siRNA internalization may not be responsible for the observed toxicity of the PGON/FITC-siRNA complexes.

\section{Conclusions}

The delivery of biologically important molecules into cells remains a field of high interest due to the potential benefits it holds for a wide variety of therapeutic and curative applications. Unfortunately, progress in this area has been limited due to the shortage of effective delivery reagents available, a problem that is even more severe when attempting to deliver to $\mathrm{T}$ cells or primary cells, which are notoriously difficult to transfect. Our research focus is dedicated to solving the problems related to siRNA internalization and delivery through systematic development of polymeric PTDMs with optimized parameters for improved intracellular delivery. In this study, the effects of varying the DP, backbone chemistry, and number of cationic charges on siRNA internalization in T cells were evaluated.

For the $\mathbf{d G}$ series, the two best performing PTDMS, $\mathbf{d G}_{\mathbf{2 0}}$ and $\mathbf{d G}_{\mathbf{3 0}}$, promoted FITC-siRNA internalization in $60 \%$ to $90 \%$ of the Jurkat T cell population, respectively. Beyond this charge content, internalization decreased significantly. The results implied that an optimal charge content was required for improved internalization. Viability of $85 \%$ or greater was observed for all PTDMs in this series. The PGON series was found to contain more DPs (n $=20-60)$ that promoted FITC-siRNA internalization into Jurkat $\mathrm{T}$ cells. These polymers could transfect up to $60-80 \%$ of the cell population, with repeat units of 20,30, 40, and 60 performing the best. When comparing the chain lengths between the two PTDM sets, both PTDMs performed similarly until their lengths were increased to 40 repeat units; at this point, PGON promotes internalization in a larger target population. In terms of the number of charges, however, which appears to be the most important factor regarding internalization 
into cells, $\mathbf{d G}$ and PGON polymers containing the same numbers of cationic guanidinium groups performed almost identically once the number of charges was increased to 40 and above. Despite its internalization results, the PGON series was found to be more toxic overall after complexing with siRNA and interacting with the cells; as low as $40-50 \%$ viability was observed in complexes with polymer repeat units of $\mathbf{P G O N}_{40}$ and $\mathbf{P G O N} \mathbf{6 0}$, while viabilities around $100 \%$ were observed for polymer alone. Through an additional series of experiments, it was shown that the total amount of internalized siRNA did not appear to strongly correlate with the observed cell toxicity. This implies that the resulting toxicity is more likely related to the final location or fate of the complex or siRNA once internalized by the cells. Light scattering and zeta potential measurements, detailed in the supporting information, indicate that the complexes formed from the dG and PGON series are extremely similar in both size and zeta potential, so this is unlikely the root cause (section V, Figure S31). Future experiments to probe the internalization pathways may prove helpful in providing answers but are not considered here. Through comparing the $\mathbf{d G}$ and PGON series, design parameters were established for effective delivery of siRNA, giving us further understanding about how the backbone architecture, length, and number of cationic charges influence siRNA internalization. At the same time, this comparison uncovered differences in cell toxicity from seemingly very similar polymers and their respective siRNA complexes.

\section{Supplementary Material}

Refer to Web version on PubMed Central for supplementary material.

\section{Acknowledgments}

This work was funded by the NIH (T32 GMO8515) and NSF (CHE-0910963 and DMR-1308123). The authors would like to thank Mr. Nicholas D. Posey for feedback on early drafts of this manuscript. The authors would also like to thank Mr. Joel M. Sarapas for assistance with vesicle preparation, Mr. Joe A. Torres for assistance with gel electrophoresis, and Dr. Rachel Letteri for advice on size and zeta potential sample preparation. Mass spectral data were obtained at the University of Massachusetts Mass Spectrometry Facility, which is supported in part by NSF. Flow cytometry data were obtained using the Flow Cytometry Core Facility at the University of Massachusetts Amherst, which is supported in part by NSF.

\section{References}

1. deRonde BM, Tew GN. Biopolymers. 2015; 104(4):265-280. [PubMed: 25858701]

2. Heitz F, Morris MC, Divita G. Brit J Pharmacol. 2009; 157:195. [PubMed: 19309362]

3. Vives E, Brodin P, Lebleu B. J Biol Chem. 1997; 272:16010-16017. [PubMed: 9188504]

4. Mitchell DJ, Kim DT, Steinman L, Fathman CG, Rothbard JB. J Pept Res. 2000; 56:318-325. 84. [PubMed: 11095185]

5. Wender PA, Mitchell DJ, Pattabiraman K, Pelkey ET, Steinman L, Rothbard JB. Proc Natl Acad Sci USA. 2000; 97:13003-13008. [PubMed: 11087855]

6. Green M, Loewenstein PM. Cell. 1988; 55:1179-1188. [PubMed: 2849509]

7. Frankel AD, Pabo CO. Cell. 1988; 55:1189-1193. [PubMed: 2849510]

8. Joliot A, Pernelle C, Deagostinibazin H, Prochiantz A. Proc Natl Acad Sci USA. 1991; 88:18641868. [PubMed: 1672046]

9. Fawell S, Seery J, Daikh Y, Moore C, Chen LL, Pepinsky B, Barsoum J. Proc Natl Acad Sci USA. 1994; 91:664-668. [PubMed: 8290579] 
10. Cooley CB, Trantow BM, Nederberg F, Kiesewetter MK, Hedrick JL, Waymouth RM, Wender PA. J Am Chem Soc. 2009; 131:16401-16403. [PubMed: 19860416]

11. Derossi D, Joliot AH, Chassaing G, Prochiantz A. J Biol Chem. 1994; 269:10444-10450. [PubMed: 8144628]

12. Sgolastra F, deRonde BM, Sarapas JM, Som A, Tew GN. Acc Chem Res. 2013

13. Lindgren M, Langel U. Cell-Penetrating Peptides: Methods and Protocols. 2011; 683:3-19.

14. Siprashvili Z, Reuter JA, Khavari PA. Mol Ther. 2004; 9:721-728. [PubMed: 15120333]

15. Opalinska JB, Gewirtz AM. Nat Rev Drug Discov. 2002; 1:503-514. [PubMed: 12120257]

16. Futaki S, Suzuki T, Ohashi W, Yagami T, Tanaka S, Ueda K, Sugiura Y. J Biol Chem. 2001; 276:5836-5840. [PubMed: 11084031]

17. Morris MC, Depollier J, Mery J, Heitz F, Divita G. Nat Biotechnol. 2001; 19:1173-1176. [PubMed: 11731788]

18. Geihe EI, Cooley CB, Simon JR, Kiesewetter MK, Edward JA, Hickerson RP, Kaspar RL, Hedrick JL, Waymouth RM, Wender PA. Proc Natl Acad Sci USA. 2012; 109:13171-13176. [PubMed: 22847412]

19. Kolonko EM, Kiessling LL. J Am Chem Soc. 2008; 130:5626-1. [PubMed: 18393495]

20. Kolonko EM, Pontrello JK, Mangold SL, Kiessling LL. J Am Chem Soc. 2009; 131:7327-7333. [PubMed: 19469577]

21. Strong LE, Kiessling LL. J Am Chem Soc. 1999; 121:6193- 6196.

22. Gaour AE, Dabkowsbriel GJ, Madkki JM, Nelson CF, Nüsslein K, Tew GN. Biomacromolecules. 2008; 9:2980-3. [PubMed: 18850741]

23. Hennig A, Gabriel GJ, Tew GN, Matile S. J Am Chem Soc. 2008; 130:10338-10344. [PubMed: 18624407]

24. Treat NJ, Smith D, Teng C, Flores JD, Abel BA, York AW, Huang F, McCormick CL. ACS Macro Lett. 2012; 1:100-104. [PubMed: 22639734]

25. Kim SH, Jeong JH, Ou M, Yockman JW, Kim SW, Bull DA. Biomaterials. 2008; 29:4439-4446. [PubMed: 18725170]

26. Ou M, Wang XL, Xu R, Chang CW, Bull DA, Kim SW. Bioconjug Chem. 2008; 19:626-633. [PubMed: 18314939]

27. Kim SH, Jeong JH, Kim TI, Kim SW, Bull D. A Mol Pharm. 2009; 6:718- 726. [PubMed: 19055368]

28. Bang EK, Gasparini G, Molinard G, Roux A, Sakai N, Matile S. J Am Chem Soc. 2013; 135:20882091. [PubMed: 23363440]

29. Gasparini G, Bang EK, Molinard G, Tulumello DV, Ward S, Kelley SO, Roux A, Sakai N, Matile S. J Am Chem Soc. 2014; 136:6069-6074. [PubMed: 24735462]

30. McKinlay CJ, Waymouth RM, Wender PA. J Am Chem Soc. 2016; 138:3510-3517. [PubMed: 26900771]

31. Ivin KJ, Mol JC. 1997:224-259.

32. Lienkamp K, Tew GN. Chem Eur J. 2009; 15:11784-11800. [PubMed: 19798714]

33. Tezgel Ö, Telfer JC, Tew GN. 2011; 12:3078-83.

34. deRonde BM, Torres JA, Minter LM, Tew GN. Biomacromolecules. 2015; 16(10):3172-3179. [PubMed: 26324222]

35. Som A, Tezgel O, Gabriel GJ, Tew GN. Angew Chemie - Int Ed Engl. 2011; 50:6147-50.

36. deRonde BM, Posey ND, Otter R, Caffrey LM, Minter LM, Tew GN. Biomacromolecules. 2016 in press.

37. Som A, Reuter A, Tew GN. Angew Chemie - Int Ed. 2012; 51:980-983.

38. deRonde BM, et al. Chemistry - a European Journal. 2015; 21(7):3013-3019.

39. Sgolastra F, Minter LM, Osborne BA, Tew GN. Biomacromolecules. 2014; 15:812-20. [PubMed: 24506414]

40. Tezgel Ö, Gonzalez-Perez G, Telfer JC, Osborne BA, Minter LM, Tew GN. Mol Ther. 2013; 21:201-9. [PubMed: 23070119] 
41. Agrawal N, Dasaradhi P, et al. Microbiol Mol Biol Rev. 2003; 67(4):657-685. [PubMed: 14665679]

42. Sharei B, et al. PNAS. 2013; 110:2082-7. [PubMed: 23341631]

43. Alekseev O, Richardson R, et al. Reproductive Biology and Endocrinology. 2009; 7:45. [PubMed: 19439102]

44. Wolf Y, Pritz S, Abes S, Bienert M, Lebleu B, Oehlke J. Biochemistry. 2006; 45:14944-14954. [PubMed: 17154532]

45. Nishihara M, Perret F, Takeuchi T, Futaki S, Lazar AN, Coleman AW, Sakai N, Matile S. Org Biomol Chem. 2005; 3:1659-1669. [PubMed: 15858647]

46. Bang EK, Lista M, Sforazzini G, Sakai N, Matile S. Chem Sci. 2012; 3:1752- 1763.

47. Ivanov AI. Methods Mol Biol. 2008; 440:15-33. [PubMed: 18369934]

48. Ivanov AI. Methods Mol Biol. 2014; 1174:3-18. [PubMed: 24947371]

49. Lundberg M, Wikstrom S, Johansson M. Mol Ther. 2003; 8:143-150. [PubMed: 12842437]

50. Richard JP, Melikov K, Vives E, Ramos C, Verbeure B, Gait MJ, Chernomordik LV, Lebleu B. J Biol Chem. 2003; 278:585-590. [PubMed: 12411431]

51. Trabulo S, Cardoso AL, Mano M, Pedroso de Lima M. Pharmaceuticals. 2010; 3:961-993. [PubMed: 27713284]

52. Vercauteren D, Vandenbroucke RE, Jones AT, Rejman J, Demeester J, De Smedt SC, Sanders NN, Braeckmans K. Mol Ther. 2010; 18:561-569. [PubMed: 20010917]

53. Goffinet C, Keppler OT. FASEB J. 2006; 20:500-502. [PubMed: 16401643]

54. Marodon G, Mouly E, Blair EJ, Frisen C, Lemoine FM, Klatzmann D. Blood. 2003; 101:34163423. [PubMed: 12511423]

55. Zhang YF, Lu HZ, LiWang P, Sili U, Templeton NS. Mol Ther. 2003; 8:629-636. [PubMed: 14529836]

56. Mantei A, Rutz S, Janke M, Kirchhoff D, Jung U, Patzel V, Vogel U, Rudel T, Andreou I, Weber M, Scheffold A. Eur J Immunol. 2008; 38:2616-2625. [PubMed: 18792414]

57. Freeley M, Long A. Biochem J. 2013; 455:133-147. [PubMed: 24070422]

58. Lai W, Chang CH, Farber DL. J Immunol Methods. 2003; 282:93-102. [PubMed: 14604544]

59. McManus MT, Haines BB, Dillon CP, Whitehurst CE, van Parijs L, Chen JZ, Sharp PA. J Immunol. 2002; 169:5754-5760. [PubMed: 12421955]

60. Fedorov Y, Anderson EM, Birmingham A, Reynolds A, Karpilow J, Robinson K, Leake D, Marshall WS, Khvorova A. RNA. 2006; 12:1188-1196. [PubMed: 16682561]

61. Jackson AL, Linsley PS. Nat Rev Drug Discovery. 2010; 9:57-67. [PubMed: 20043028]

62. Persengiev SP, Zhu X, Green MR. RNA. 2004; 10:12-18. [PubMed: 14681580]

63. Semizarov D, Frost L, Sarthy A, Kroeger P, Halbert DN, Fesik SW. Proc Natl Acad Sci USA. 2003; 100:6347-6352. [PubMed: 12746500]

64. Jackson AL, Burchard J, Schelter J, Chau BN, Cleary M, Lim L, Linsley PS. RNA. 2006; 12:1179-1187. [PubMed: 16682560]

65. Barik S. Nature Biotechnology. 2006; 24:796- 797. 

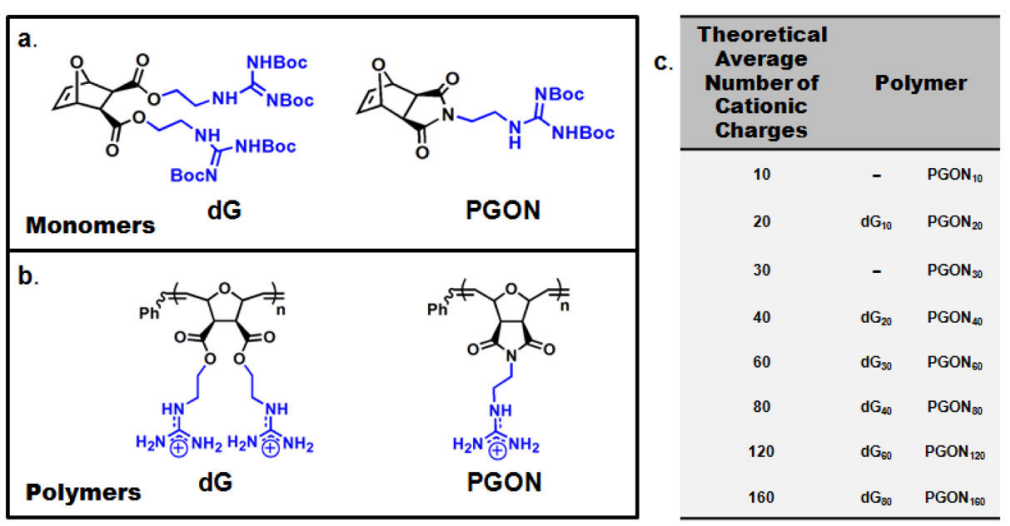

Figure 1.

Chemical structures of monomers and polymers used in this study. (a) dG and PGON monomers (b) dG and PGON polymers. Blue represents cationic moieties (c) Table describing polymer nomenclature and corresponding average number of cationic charges contained in each polymer. 
Length Comparison

a.

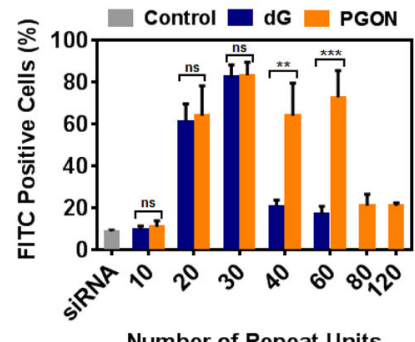

C.

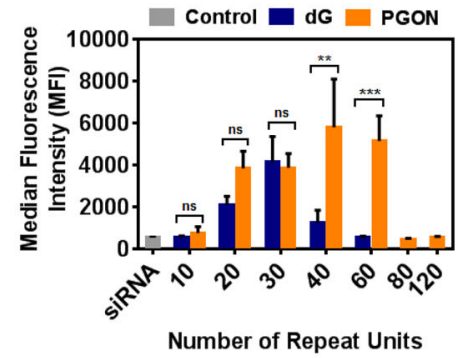

Charge Comparison

b.

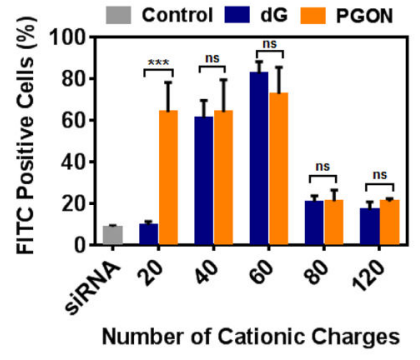

d.

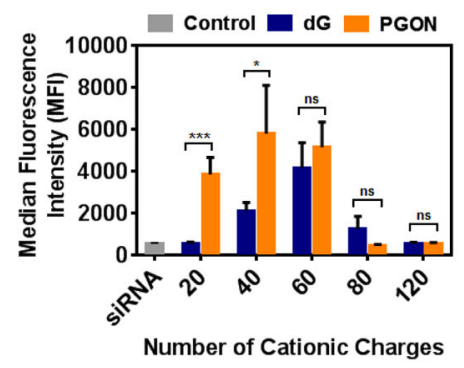

Figure 2.

FITC-siRNA internalization of Jurkat T cells using dG and PGON-based PTDMs.

Comparison of percentage of FITC positive cells, in cell populations treated with dG/FITCsiRNA and PGON/FITC-siRNA complexes, prepared using 50 nM FITC-siRNA, based on (a) polymer length and (b) charge content. Comparison of MFI in cell populations treated with dG/siRNA and PGON/siRNA complexes, based on (c) polymer length and (d) charge content. Jurkat T cells (cell density $=4 \times 10^{5}$ cells $/ \mathrm{mL}$ ) were treated with PTDM $/$ FITCsiRNA complexes with an N:P ratio of 8:1 in complete medium for $4 \mathrm{hr}$ at $37^{\circ} \mathrm{C}$. All data was compared to an untreated control. Data represents the mean \pm SEM of three independent experiments. *, $\mathrm{p}<0.05 ; * *, \mathrm{p}<0.01 ; * * *, \mathrm{p}<0.001 ; \mathrm{ns}=$ not significant, as calculated by the unpaired two-tailed student t-test. * represents the significance between dG and PGON PTDMs with the same relative charge content or polymer length, where appropriate. 


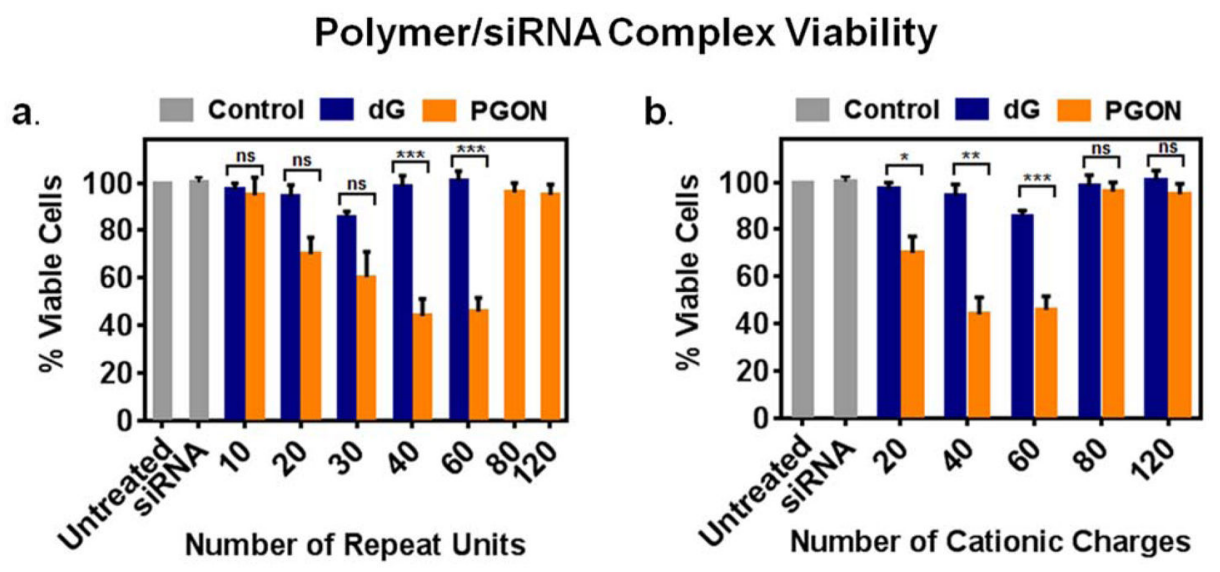

Figure 3.

Percent viable cells following staining with 7-AAD. Jurkat T cells (cell density $=4 \times 10^{5}$

cells/mL) were treated with (a) dG/siRNA and PGON/siRNA complexes, prepared using 50 nM FITC-siRNA, in terms of number of repeat units and in terms of (b) cationic charges in complete medium for $4 \mathrm{hr}$ at $37^{\circ} \mathrm{C}$. PTDM/FITC-siRNA complexes were prepared at an N:P ratio of 8:1. All data was normalized to an untreated control. Data represents the mean \pm SEM of three independent experiments. *, $\mathrm{p}<0.05$; **, $\mathrm{p}<0.01$; ***, $\mathrm{p}<0.001$; ns $=$ not significant, as calculated by the unpaired two-tailed student t-test. * represents the significance between dG and PGON PTDMs with the same relative charge content or polymer length, where appropriate. 


\section{PTDM Only Viability}

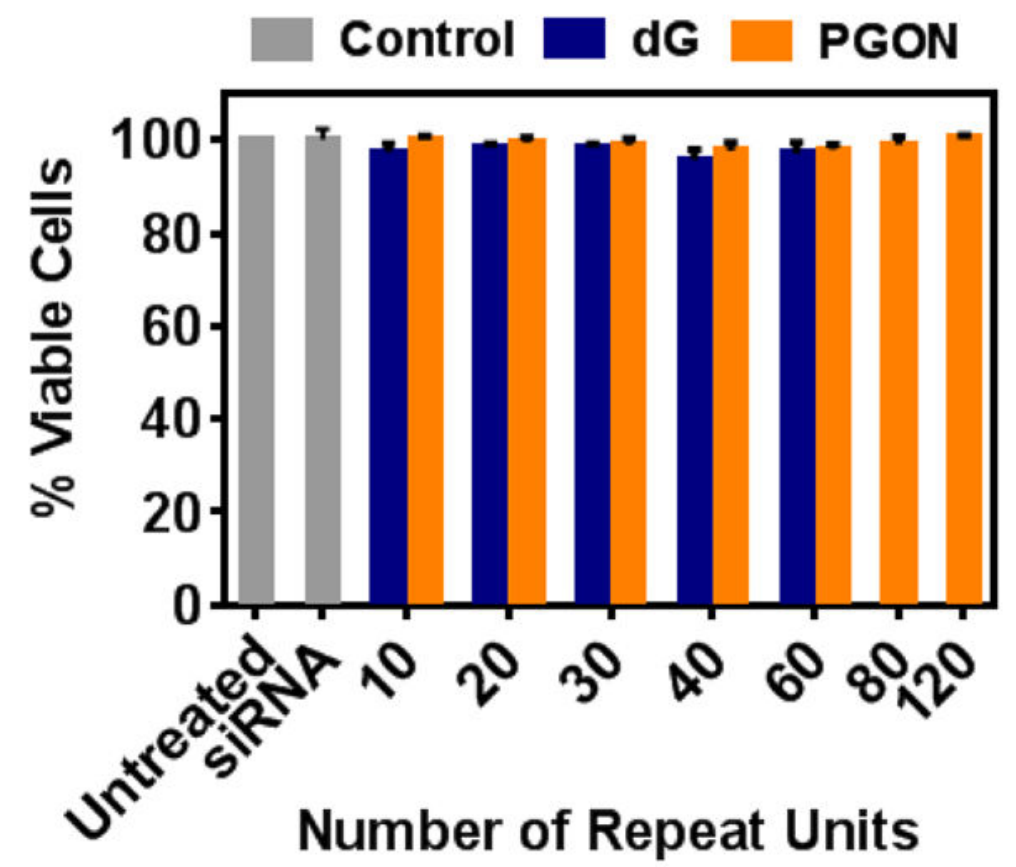

Figure 4.

Percent viable cells following staining with 7-AAD. Jurkat T cells (cell density $=4 \times 10^{5}$ cells $/ \mathrm{mL}$ ) were treated with $\mathbf{d G}$ and PGON only in complete medium for $4 \mathrm{hr}$ at $37^{\circ} \mathrm{C}$. PTDM/FITC-siRNA complexes were prepared at an N:P ratio of 8:1. All data was normalized to an untreated control. Data represents the mean \pm SEM of three independent experiments. *, $\mathrm{p}<0.05 ; * *, \mathrm{p}<0.01 ; * * *, \mathrm{p}<0.001 ; \mathrm{ns}=$ not significant, as calculated by the unpaired two-tailed student t-test. * represents the significance between $\mathbf{d G}$ and PGON PTDMs with the same relative charge content or polymer length, where appropriate. 

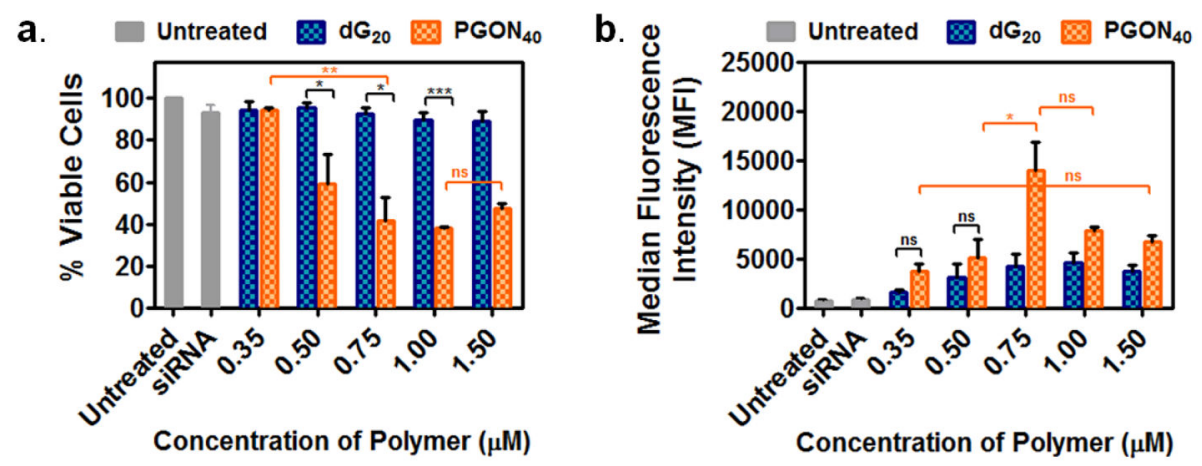

Figure 5.

(a) Percent viable cells, following staining with 7-AAD, in populations treated with varied concentrations of PTDM/FITC-siRNA complexes to compare with the concentration used in the original experiments $(0.5 \mu \mathrm{M})$. (b) MFI of cell populations treated with varied concentrations of PTDM/FITC-siRNA complexes. Jurkat T cells (cell density $=4 \times 10^{5}$ cells $/ \mathrm{mL}$ ) were treated with varying concentrations of $\mathbf{d G}_{\mathbf{2 0}} / \mathrm{siRNA}$ complexes $\mathbf{P G O N} \mathbf{4 0}_{\mathbf{4 0}} /$ siRNA complexes in complete medium for $4 \mathrm{hr}$ at $37^{\circ} \mathrm{C}$. PTDM/FITC-siRNA complexes were prepared at an $\mathrm{N}: \mathrm{P}$ ratio of 8:1. All data was normalized to an untreated control. Data represents the mean \pm SEM of three independent experiments. ${ }^{*}, \mathrm{p}<0.05 ; * *, \mathrm{p}<0.01$; ***, $\mathrm{p}<0.001 ; \mathrm{ns}=$ not significant, as calculated by the unpaired two-tailed student t-test. 

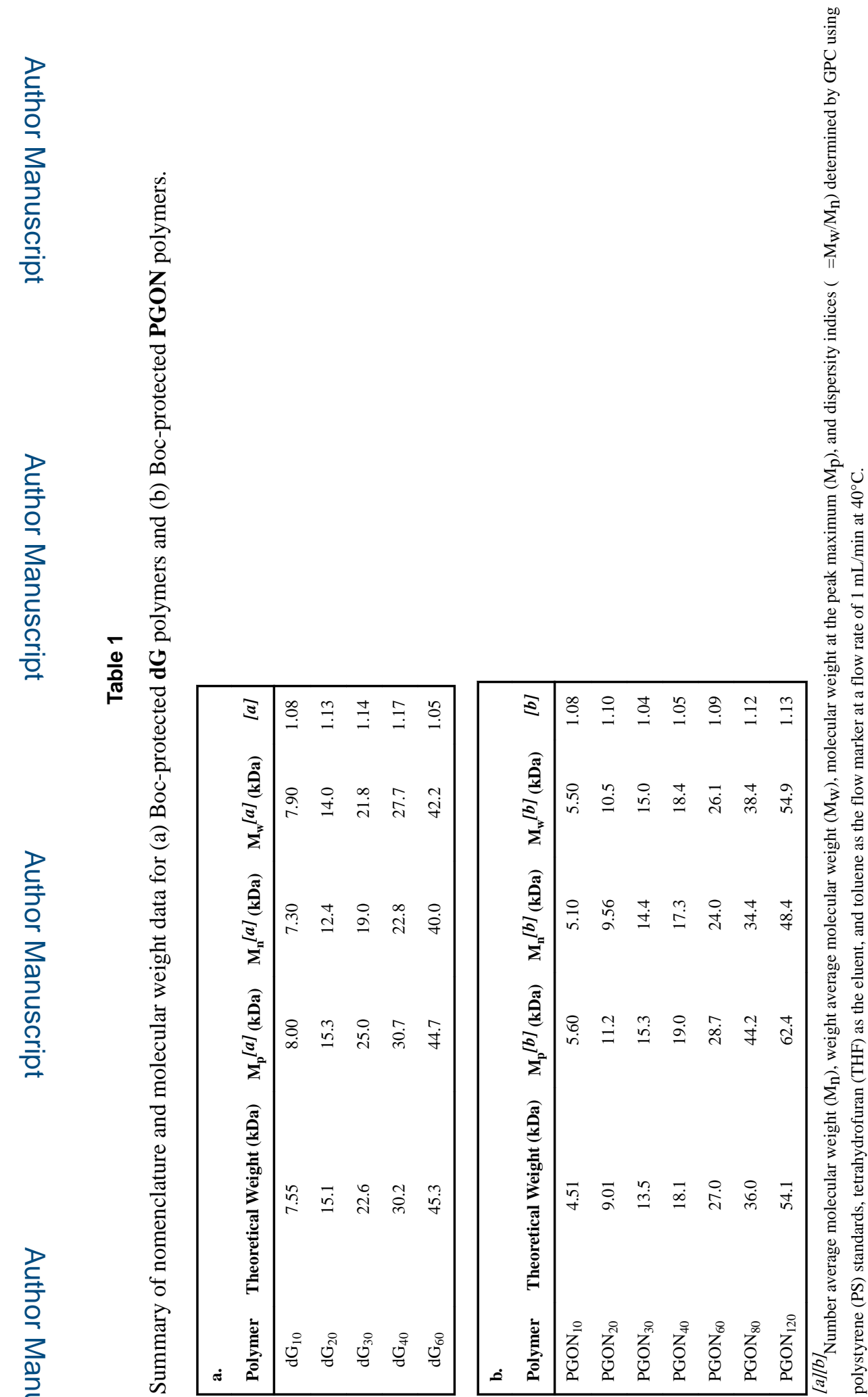

Biomacromolecules. Author manuscript; available in PMC 2016 November 03. 